Faculdade de Ciências Econômicas UFRGS
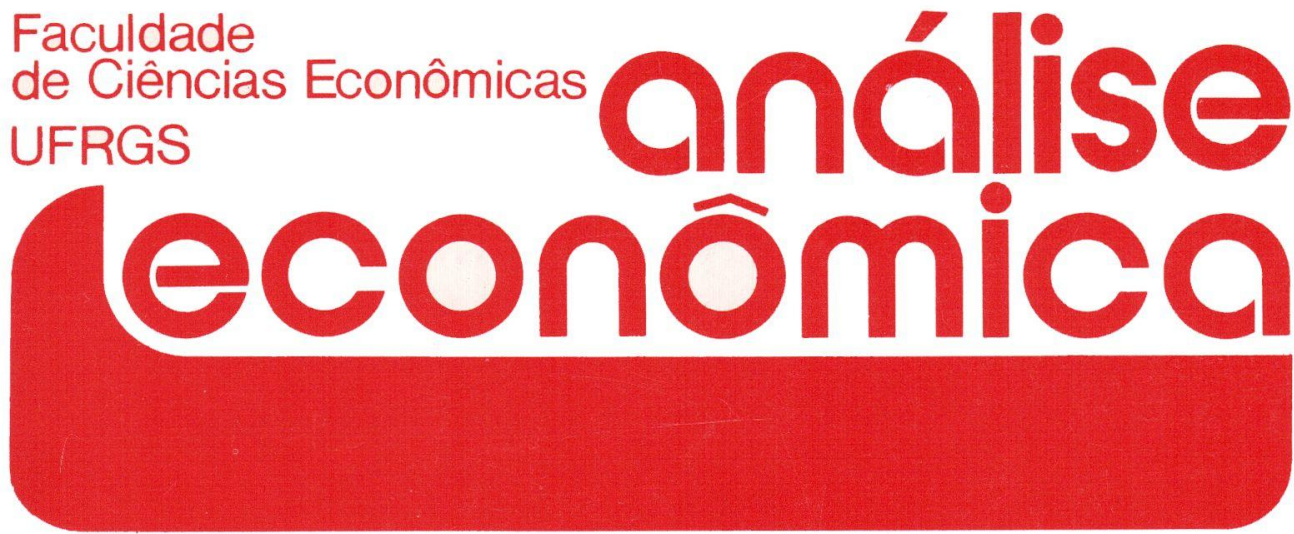

- INDEXAÇĀo SALARIAL: UMA ABORDAGEM MACROECONÓMICA Jo Anna Grav

- AJUSTE NO EMPREGO E PRODUTIVIDADE NA DECADA DE OITENTA

Carlos Antônio Luque José Paulo Zeeteno Chahad

- O CONSUMIDOR KEYNESIANO Marcelo Córtes Neri

- HETEROGENEIDADE DO TRABALHO E TAXA DE LUCRO EM MARX

Francisco Cribari Neto

- ECONOMIAS DE ESCALA: UMA REVISĀO Jesiel de Marco Gomes

- Concentraçấo bancária no BRASIL

Marcelo Resende

- NOYOS RUMOS PARA O SETOR ELETRICO NO BRASIL

Adriano Pires Rodrigues

Eduardo da Cunha Vianna

- OFERTA E DEMANDA DE FRANGO DE CORTE NO BRASIL

Narciso Gonçalves de Castro et alii

- ANÁLISE ECONÔMICA DA IRRIGAÇÃo DO MILHO

Lúcia M Schirmer

Juvir Luiz Mattuella

- REFLORESTAMENTO NO BRASIL. Carlos José Caetano Bacha

- ESCOLHA DE TECNOLOGIA EM ESTRUTURA DE PRINCIPAL AGENTE Kyle D. Kauffma:

- A QUESTÁo DEMOGRÁfica e A PRAXEOLOGIA

Anton Karl Biedermann et alii
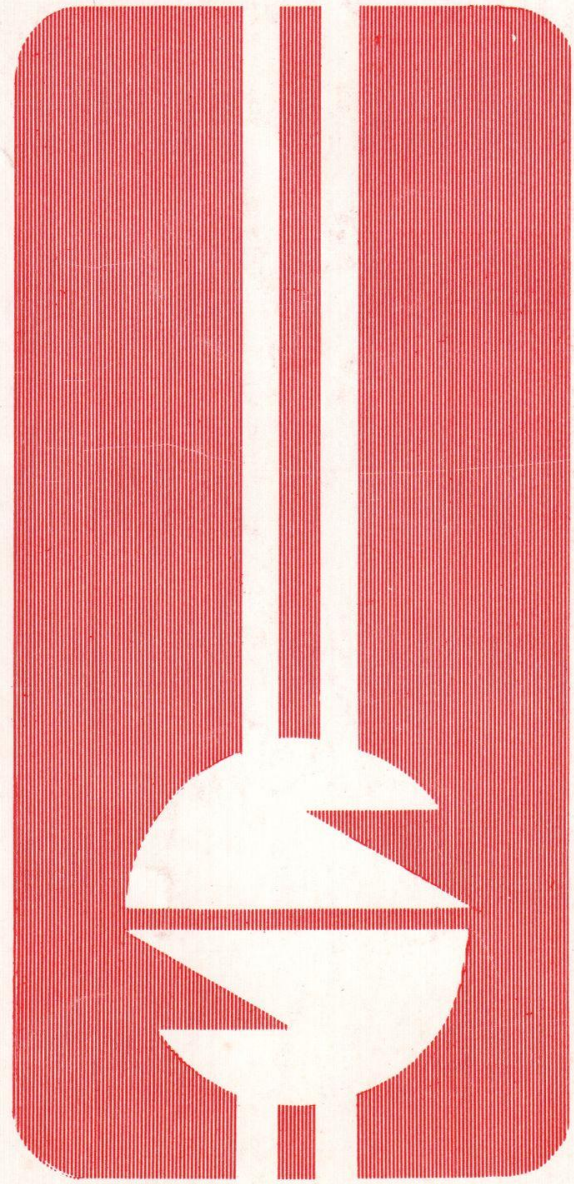
UNIVERSIDADE FEDERAL DO RIO GRANDE DO SUL

Reitor: Prof. Tuiskon Dick

FACULDADE DE CIÉNCIAS ECONÔMICAS

Diretora: Prof ${ }^{\text {a }}$ Yeda Rorato Crusius.

CENTRO DE ESTUDOS E PESQUISAS ECONÔMICAS

Diretor: Reinaldo Ignacio Adams

DEPARTAMENTO DE CIÉNCIAS ECONÔMICAS

Chefe: Prof. Fernando Ferrari Filho

CURSO DE POS-GRADUAÇÄO EM ECONOMIA

Coordenador: Prof. Nali de Jesus de Souza

CURSO DE PÓS-GRADUAÇĀO EM ECONOMIA RURAL

Coordenador: Prof. Atos Freitas Grawunder

CONSELHO EDITORIAL: Achyles Barcelos da Costa, Aray Miguel Feldens, Atos Freitas Grawunder, Carlos Augusto Crusius, Ernani Hickmann, João Rogério Sanson, Juvir Luiz Mattuella, Maria Imilda da Costa e Silva, Nali de Jesus de Souza, Nuno Renan Lopes de Figueiredo Pinto, Otilia Beatriz Kroeff Carrion, Otto Guilherme Konzen, Paulo Alexandre Spohr, Pedro Cezar Dutra Fonseca, Reinaldo Ignacio Adams, Roberto Camps Moraes, Valter José Stülp, Yeda Rorato Crusius, David Garlow (Wharton Econometrics Forecasts Association, E.U.A.), Edgar Augusto Lanzer (UFSC), Eleutério F.S. Prado (USF), Fernando Holanda Barbosa (FGV/RJ), Gustavo Franco (PUC/RJ), Joaquim Pinto de Andrade (UnB), Juan H. Moldau (USP), Werner Baer (Univ. de Illinois, E.U.A.).

COMISSĀO EDITORIAL: Atos Freitas Grawunder, Pedro Cezar Dutra Fonseca, Reinaldo Ignacio Adams e Roberto Camps Moraes.

EDITOR: Nali de Jesus de Souza

SECRETARIA: Maria Ivone de Mello (normalização), Vanete Ricacheski (revisão de textos).

FUNDADOR: Prof. Antônio Carlos Santos Rosa

Os materiais publicados na revista Análise Econômica são de exclusiva responsabilidade dos autores. É permitida a reprodução total ou parcial dos trabalhos, desde que seja citada a fonte.

Aceita-se permuta com revistas congêneres. Aceitam-se, também, livros para divulgação, elaboração de resenhas ou recenșões.

Toda correspondência, material para publicação, assinaturas e - permutas devem ser dirigidos ao seguinte destinatário:

\section{PROF. NALI DE JESUS DE SOUZA}

Revista Análise Econômica

Av. João Pessoa, 52

CEP 90040-000 - PORTO ALEGRE (RS), BRASIL

Telefones: (051) 228-1633 - 224-6024 ramais 3440 e 3348

Fax: (051) 225-1067 


\title{
A SITUAÇÃO ATUAL DOS DADOS SOBRE REFLORESTAMENTO NO BRASIL
}

\author{
Carlos José Caetano Bacha*
}

\section{SINOPSE}

O objetivo deste trabalho é o de analisar as fontes de dados sobre reflorestamento no Brasil. Foram analisados os dados dos Censos Agropecuáriọ, da publicaçắo Silvicultura e dos Cadastros do extinto Insututo Brasileiro de Desenvolvimento Florestal (IBDF).

Concluf́mos que se deve dar, sempre que possfvel, preferência à utilização dos dados dos Censos Agropecuários. Isso não exclui o uso dos dados da publicaçăo Silvicultura, quando o foco de antilise for a área. Mas os dados dos Cadastros do IBDF devem ser utilizados com recorvas.

A análise dos dados dos Censos Agropecuários e da Silvicultura mostram um grande crescimento do reflorestamento no Brasil, mas ressaitando que esse reflorestamento está concentrado em Minas Gerais, São Paulo, Paraná, Santa Catarina, Rio Grande do Sul e Mato Grosso do Sul.

\section{INTRODUÇÃO}

A literatura sobre meio ambiente tem discutido muito o efeito estufa, ou seja, o crescimento da concentração de gás carbono $\left(\mathrm{CO}_{2}\right)$, metano $\left(\mathrm{CH}_{4}\right)$, clorofluorcarbono $(\mathrm{CFC})$ e outros elementos na atmosfera, que desencadeiam modificações do clima e dos níveis dos oceanos. Para acabar com esse efeito, é necessário substituir as fontes atuais de combustfreis (obtidos pela combustão de materiais e com exaltação de gás carbono) por combustfiveis a base de hidrogênio. Mas enquanto isso não ocorre, o efeito estufa pode ser amenizado pela fixação do $\mathrm{CO}_{2}$ na fitomassa. Por essa razão, os ambientalistas pressiionam pela redução do ritmo de alterą̧ão da cobertura florestal no mundo.

No Brasil, um grupo interdisciplinar do Instituto de Estudos Avançados da USP elaborou o Projeto Floram, que é uma proposta de reflorestamento, em diversas partes do Pars, que cumpriria as funçôes de ser

* Professor da ESALQ/USP

\begin{tabular}{|l|l|l|l|l|}
\hline ANÁLISE ECONÔMICA & ANO 10 & № 17 & MARÇO/92 & P.141-155 \\
\hline
\end{tabular}


utilizado economicamente e/ou restabelecer parte do equillorio ecologic0. O Projeto Floram propõe reflorestar 20 milhões de hectares $(2,3 \%$ do território brasileiro) em um prazo de 20 a 30 anos..$^{I}$

$O$ Projeto Floram inclui florestas sociais, florestas para reabilitação de solos, florestas para bloqueio de desertificação, floresta para reperenização de drenagem, florestas hídricas de interesse ś́cio-econômico e cultural, florestas e bosques para bloqueio de conturbação, bosques e áreas verdes periurbanas, revegetação e bosqueamentos viáveis para as regiōes semi-áridas brasileiras. Com o Floram, o Brasil contribuiria para diminuir o excesso de $\mathrm{CO}_{2}$ na atmosfera mundial.

Antes dessa proposta do Floram, tivemos alguns programas de incentivos ao reflorestamento. O governo federal realizou, de 1966 a 1987, um amplo programa de reflorestamento com incentivos fiscais. BACHA (1991) analisou esse programa, mostrando que os incentivos fiscais autaram como indutores de reflorestamento, mas ressaltando, também, a importância da demanda criada pela política econômica de expansão do setor de celulose e papel, pela siderurgia a carvão vegetal e pelo programa de substituição energética. Apesar de seu impacto positivo na expansão do reflorestamento, o programa de incentivos fiscais teve aspectos adversos, a saber: as empresas reflorestadoras criaram grandes estabelecimentos, contribuindo para a concentração da posse da terra; os incentivos fiscais foram apropriados por poucos agentes (pessoas jurfdicas), promovendo maior concentração da riqueza; e houve um planejamento incompleto do reflorestamento, que levou ao estabelecimento de plantio em áreas sem destinação econômica ou em áreas não ideais.

Outro programa federal de incentivo ao reflorestamento foi o REPEMIR (Programa de Reflorestamento de Pequenos e Médios Imóveis Rurais). Esse programa foi lançade na segunda metade da década de 70 e tinha como cbjetivo fornecer ao pequeno e médio proprietário rural uma fonte de material lenhoso, refletindo positivamenie na economia agricola e nas atividades conservacionistas.

O REPEMIR foi um programa de financiamento subsidiado ao plantio e não de incentivos fiscais. Os impactos daquele programa sobre a área reflorestada foram bem menores do que os gerados pelo programa de incentivos fiscais.

BERGAMASCO e BERGAMASCO (1988) avaliaram esse programa em São Paulo. Até 1987, haviam cadastrados, nesse estado, $5.065,51$ ha reflorestados atraves do REPEMIR, sendo que apenas ao longo do ano de 1984 foram reflorestados com incentivos fiscais $\mathbf{1 8 . 4 5 0}$ ha em São Paulo (BACHA, 1991, p. 155).

\footnotetext{
1 Uma discusstán sobre o Projeto Floram encontra-se na Revista Estudos Avançados, volume 4, número 9 do IEA/USP referente a maio/agosto de 1990 . São vários artigos analisando o Projeto Floram.
} 
Em Minas Gerais, o REPEMIR também contribuiu pouco para a área reflorestada. Até março de 1986, esse programa tinha reflorestado uma área de 14.350,35 ha (veja ASSIS et alii, 1986, p. 91), enquanto ao longo do ano de 1984 tinham sido reflorestados 68.130 ha com incentivos fiscais (BACHA, 1991, p. 155).

Uma das razões do menor impacto do REPEMIR sobre o reflorestamento, em relação ao Programa de Incentivos Fiscais para Reflorestamento, pode ser o maior volume de recursos federais destinados a esse último em relação ao primeiro. O trabalho IBDF (1985) nos informa que em 1984 foram alocados Cr\$400 milhões ao REPEMIR ${ }^{2}$ e Cr\$230 biIhões ao Programa de Incentivos Fiscais ao Reflorestamento ${ }^{3}$.

Influenciado pela grande seca nordestina de 1979 a 1983 e pelo bom desempenho da algarobeira em áreas semi-áridas do Nordeste brasileiro, o Governo Federal realizou o Projeto Algaroba no perfodo de 1985 a 1988. Esse projeto consistiu na produção e distribuição de mudas de algarobeiras, prestação de assistência técnica e apoio financeiro aos produtores da área da SUDENE.

R.Projeto Algaroba foi realizado utilizando recursos do FINSOCIAL e do BNDES, e foi coordenado pela Secretaria Nacional de Produção Agropecuária (SNA.F), do Ministério da Agricultura, com a participação das Secretarias de Agricultura dos Estados do Nordeste. Segundo SILVA (1989, p. 23) o Projeto Algaroba atendeu 8,3 mil pequenos produtores rurais na implantação de 18,8 mil hectares em 540 municrpios da área da SUDENE. 4

Nas décadas de 70 e 80 , também foram implementădos alguns programas estaduais de incentivos ao reflorestamento. BACHA (1991) comenta o Prodemata/Reflorestamento, o MG - II e o Planoroeste - II em Minas Gerais. Esses programas também reflorestaram uma área pequena, comparada com a reflorestada com incentivos fiscais. Atê março de 1986 tinham sido reflorestados, em Minas Gerais, 30.ó40,36 ha através desses

2 Esse valor foi inferido da seguinte afirmação: "Os recursos destinẩos ao REPEMIR totalizaram Cr\$ 400 milhỏes, quantia suficiente pars o plantio de aproximadamente 120 mil hectares de florestas e produçăo de 130 milhóes de mudas de essências de rápido crescimento" (IBDF, 1985, p. 19).

3 Desde o final de 1974, esse programa passou a se chamar FISET - Florestamentu e Reflorestamento.

4 Esse resultado foi bem menor do que o inicialmente previsto. O primeiro escopo do Projeto Algaroba previa o plantio de 1,5 milhóes de hectares, atingindo 290 mil produtores rurais 0 vigoraria de 1984 a 1988 . Ao ser aprovado para o perfodo de 1985 a 1988 , a meta do Projeto Algaroba foi reduzida ao plantio de 60 mil hectares, beneficiando 20 mil pequenos produtores rurais. 
programas estaduais.

Alem dos programas governamentais, as empresas reflorestam com recursos próprios ou elaboram projetos de integração de pequenos produtores no reflorestamento.

Mas qual a dimensão da área reflorestada atual? Muitos trabalhos apresentam dados de área reflorestada com incentivos fiscais (como BEATTIE e FERREIRA, 1978, EXAME, 1980 e IBDF, 1985). Mas ocorreram fraudes com a utilização desses recursos e houve plantios com recursos próprios e através de outros programas públicos.

$O$ objetivo deste trabalho $\varepsilon$ o de analisar as fontes de dados existentes sobre reflorestamento no Brasil, mostrando suas limitaçōes e divergências. A partir dessa avaliação, poderemos analisar a evolução do reflorestamento e onde ele se concentra.

No item dois analisamos as fontes de dados sobre reflorestamento. No item três analisamos a evolução do reflorestamento no Prasil e sua concentração por Estado. No item quatro apresentamos algumas conclusōes.

\section{OS DADOS SOBRE REFLORESTAMENTO}

Existem três fontes de dados sobre o número de árvores e área reflorestadas no Brasil, a saber: os Censos Agropecuários, a publicação Silvicultura e os dados cadastrais do extinto IBDF.

Antes de passarmos à análise das fontes de dados, é necessário esclarecer o que significam algumas expressões que elas utilizam. A expressão "arvores plantadas existentes eln certa data" (ou como nós preferimos chamar, "arvores cultivadas existentes em certa data") se refere ao estoque de árvores existentes enc certo momento do tempo, que foram plantadas naquele ano e nos anos anteriores. A expressão "árvores plantadas no ano x" são as árvores implantadas ao longo do ano x. E "árvores abatidas no ano $\mathrm{x}$ " são as que foram derrubadas ao longo do ano $\mathrm{x}$.

Os Censos Agropecuários de 1970, 1975, 1980 e 1985 apresentam informações sobre o número de estabelecimentos que apresent?m matas plantadas, a área ocupada por essas matas e o número de árvores cultivadas existentes em $31 / 12 / 70$, em $31 / 12 / 75$, em $31 / 12 / 80$ e em $31 / 12 / 85$. Essas informaçōes foram obtidas em perguntas independentes, através de entrevista direta com todos os produtores.

As informações sobre o número de estabelecimentos e área com matas plantadas foram levantadas na pergunta sobre utilização da áreð total dos estabelecimentos. Foram computadas as áreas plantadas com essências florestais, as áreas em preparo para o plantio de essências flo- 
restais e as áreas ocupadas com viveiros de essências florestais. As informaçōes sobre o número de árvores cultivadas existentes foram levantadas em un. ó pergunta especffica, onde só se computou as árvores cultivadas existentes (e não as mudas ou as árvores que seriam plantadas).

Devidio ao exposto acirr a, a área ocupada com matas plantadas, segundo os Censos Agropecuários, sobrestima a área realmente reflorestada. De fato, observandc as informações da tabela 1 constatamos para vários estados a existência de área ocupada com matas plantadas sem existir árvores cultivadas (veja o caso de vários estados das regiốes Norte e Nordeste).

TABELA 1 - NUMERO DE ESTABELECIMENTOS QUE INFORMARAM POSSUIR MATAS PLANT ADAS, X́REAS COMT matas PLANTADAS E NÚmERo de KRVORES PI,ANTADAS.

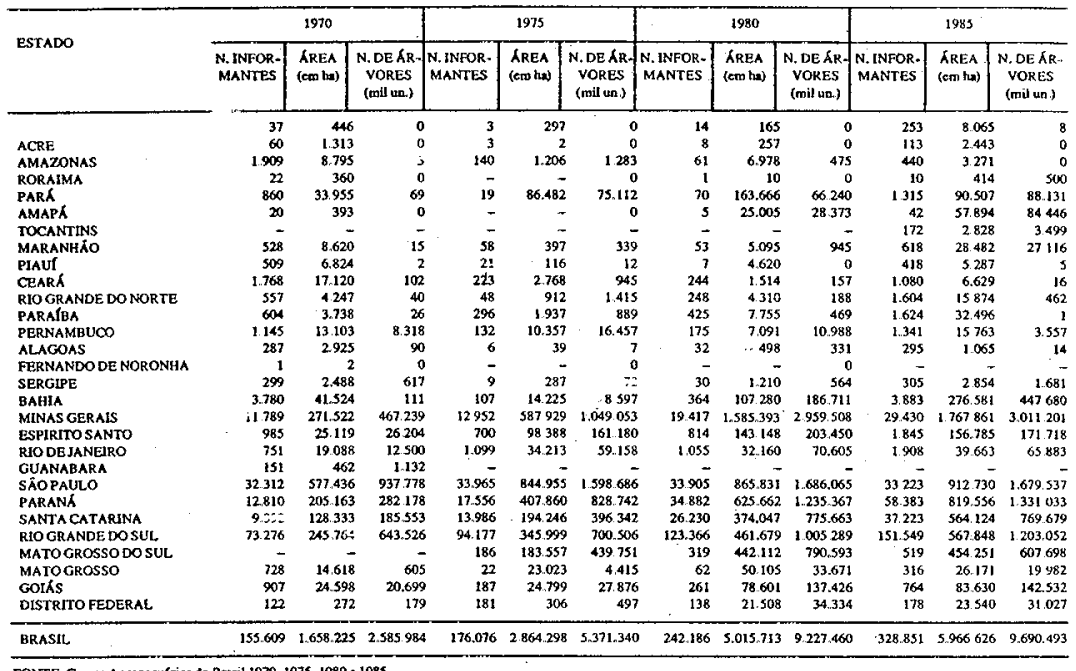

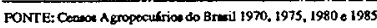

Então, se nossa preocupação for corr o que foi realmente reflorestado, deveimos, nos Censos Agropecuários, dar preferência à utilização das informaçōes sobre o número de árvores cultivadas existentes. Sobre essas, existem algumas diferenças nos Censos, a saber:

- no Censo A Aropecuário de 1970 foi pesquisado o número de árvores cultivadas que foram abatidas durante esse ano. Nos censos de 1975, 1980 e 1985 não foram pesquisados o número de árvores cultivadas que foram abatidas durante esses anos.

- Apenas nos Censos Agropecuários de 1980 e 1985 foram pesquisados: o número de árvores plantadas com e sem incentivos fiscais ao longo de 1980 e 198 '5 e o número de árvores existentes em 31/12/80 e em 31/12/85 que forsm plantadas com incentivos fiscais. 
A publicação Silvicultura foi uma pesquisa iniciada em 1974 e publicou dados de 1975 a 1984, quando foi encerrada. Os dados eram obtidos a partir de informantes diretos (os produtores agricolas e as empresas de reflorestamento e de florestamento) e indiretos (técnicos e órgãos ligados direta ou indiretamente aos setores de produção, comercialização, industrialização e fiscalização dos produtos florestais). A partir de 1985, parte das informações da Silvicultura passaram a ser coletadas pela publicação Produção Extrativa Vegetal.

No seu inf́cio, a pesquisa Silvicultura fazia a análise de 36 espécies de árvores cultivadas. Essa pesquisa nos fornece dados de área e de número de árvores cultivadas existentes em 31/12 de 1975 a 1984, e a área e o número de árvores implantadas e abatidas ao longo desses anos. As informaçōes estão disponfveis por munićpios e por especies.

As informaçōes do extinto Instituto Brasileiro de Desenvolvimento Florestal (IBDF) sobre área e número de árvores plantadas com incentivos fiscais por espécies e estados, para cada ano da série 1967 e 1984 foram publicadas por alguns trabalhos (como BEATTIE e FERREIRA, 1978, FXAME, 1980, e IBDF, 1985). Esses dados apresentam duas limitaçōes, a saber: são retirados dos cadastros dos projetos aprovados e não se referem à área efetivamente plantada com árvores, devido às fraudes e perdas no plantio; e incluern árvores cultivadas com interesse de obtenção de madeira, de frutos (caso de árvores írutfferas) e de obtenção de produtos de extração (caso da seringueira, palmito, açaizeiro e erva-mate).

Devemos utilizar com reserva os dados dos Cadastros do IBEF, pois não retratám a evelução de todo o reflorestamento, mas apenas de parte dele. BACHA (1991) utilizou os dados de área reflorestada com incentivos fiscais do IBDF para explicar a importância parcial dos incentivos fiscais como causa de reflorestamento. Esse autor tinha o objetivo de mostrar que os incentivos fiscais atuaram como indutores do reflorestamento junto com outras causas, como a demanda criada peia expansão dn setor de celulose, da siderurgia a carvão vegetal e pela substituição energética. Para tanto, considerou a área reflorestada com incentivos fiscais, para provar que, mesmo para essa porção do reflorestamento, os incentivos fiscais são apenas parte das causas da expansão do reflorestamento no Brasil.

\subsection{Comparação entre os dados da Silvicultura e os dos Censos Agropecuários.}

Embora a mesma instituição (o IBGE) proceda à coleta e à elaboração dessas duas fontes de dados, existem diferenças metodológicas significativas entre elas, a saber: 
- a Silvicultura é uma pesquisa, e como tal é elaborada sobre uma amostra. Já o Censo Agropecuário é um inquérito com todos os plantadores de árvores.

- O Censo Agropecuário faz entrevista com os informantes diretos e a Silvicultura utiliza os informantes diretos (produtores e as empresas de reflorestamento) e informantes indiretos (técnicos e orgãos ligados direta ou indiretamente aos setores de produção, comercialização, industrialização e fiscalização dos produtos florestais). Tal fato foi reconhecido pelos formuladores da Silvicultura, que o defende alegando "A base deste procedimento metodológico repousa, portanto, num sistema de fontes de informação que permita um acompanhamento global e permanente, sem omissões ou duplicações, das variáveis investigadas, por espécie florestal, no âmbito de cada munićpio, ou seja, da unidade de investigação da pesquisa" (SILVICULTURA - 1980. Volume 3, p. IX).

- As informaçōes da publicação Silvicultura sobre a área ocupada com árvores cultivadas não inclui as áreas preparadas para o plantio e as ocupadas com viveiros, como é o caso dos Censos Agropecuários. Portanto, a publicação Silvicultura pesquisa a área efetivamente reflorestada.

- A publicação Silvicultura apresenta informações mais desagregadas por especies que o Censo Agropecuário. Encontramos no Censo Agropecuário de 1975 diversas especies agregadas sob a denominação "Outras Especies", enquanto a publicaçãc Silvicultura - 1975 apresenta as informaçōes mais desagregadas. O Censo Agropecuário de 1980 nāo considerou o item "Outras Espécies", desprezando várias espécies que foram divulgadas na Silvicultura - 1980.

Nas tabelas 2 e 3 apresentamos os dados de árvores cultivadas existentes em $31 / 12 / 75$ e em $31 / 12 / 80$, respectivamente, para algumas espécies segundo o Censo Agropecuário e a Silvicultura. 


\section{TABELA 2 - ÁRVORES CULTIVADAS EXISTENTES EM 31/12/75 (em mil unidades)}

\begin{tabular}{lccc}
\hline ESPÉCIES & $\begin{array}{c}\text { CENSO } \\
(\mathrm{A})\end{array}$ & $\begin{array}{c}\text { SILVICULTURA } \\
(\mathrm{B})\end{array}$ & $\{(\mathrm{A}-\mathrm{B}) / \mathrm{B}\} .100$ \\
\hline acácia negra & 180.585 & 138.139 & 30,7 \\
algaroba & 1.880 & 624 & 201,3 \\
braacatinga & 24.747 & 8.506 & 190,9 \\
cedro & 302 & 112 & 169,6 \\
eucalipto & 3.296 .256 & 3.363 .038 & $-2,0$ \\
jacarandá & 1.553 & 1.503 & 3,3 \\
peroba & 1.028 & 363 & 183,2 \\
pinheiro & 228.293 & 190.623 & 19,8 \\
pinus & 1.539 .927 & 1.844 .977 & $-16,5$ \\
quiri & 16.342 & 8.905 & 83,5 \\
outras espécics & $80.427(*)$ & $16.537(* *)$ & 386,3 \\
\hline
\end{tabular}

FONTE: Censo Agropecuário do Brasil de 1975 e Silvicultura 1975.

NOTA: $\left.{ }^{*}\right)$ O Cenșo năo as especifica.

(**) Inclui andiroba, angico, caixeta, canela, carvalho corticeiro, casuarina, cedro japon\&s, cipreste, cuningamia, grevilha gigante, guajuvira, guapuruvu, imbuia, ipe, jacaré, jacatiráo, mogno, sabiă, sassafrass, sete-casacas, ucuubeira e vinhático.

\section{TABELA 3 - ÁRVORES CULTIVADAS EXISTENTES EM 31/12/80 (em mil unidades)}

\begin{tabular}{lrrr}
\hline ESPECIES & $\begin{array}{c}\text { CENSO } \\
(\mathrm{A})\end{array}$ & $\begin{array}{r}\text { SILVICULTURA } \\
(\mathrm{B})\end{array}$ & $\{(\mathrm{A}-\mathrm{B}) / \mathrm{B}\} .100$ \\
\hline acácia negra & 261.185 & 204.202 & 27,9 \\
andiroba & 4.139 & 6.300 & $-34,3$ \\
braecatinga & 89.410 & 26.293 & 240,0 \\
cedro & 11.831 & 2.656 & 345,4 \\
eucalipto & 5.945 .580 & 5.830 .148 & 2,0 \\
gmelina & 36.081 & 52.506 & $-31,3$ \\
pinheiro & 348.972 & 279.300 & 24,9 \\
pinus & 2.519 .057 & 2.801 .629 & $-10,1$ \\
quiri & 11.205 & 11.896 & $-5,8$ \\
outras espécies & - & $39.554\left(^{*}\right)$ & - \\
\hline TOTTAL & 9.227 .460 & 9.254 .484 & $-0,3$ \\
\hline
\end{tabular}

FONTE: Censo Agropecuário do Brasil de 1980 e Silvicultura 1980.

NOTA: (*) Inclui algarobeira, angico, caixeta, canela, carvalho corticeiro, casuarina, cedro japonks, cipreste, cuningania, grevilha gigante, guajuvira, guapuruvu, imbuia, ip\&, jacaranda, jacare, jacatiráo, mogno, peroba, sabiá, sassafias, sete-casacas, ucuubeira e vinhático. 
O exame das tabelas 2 e 3 mostra-nos que os dados da Silvicultura e do Censo Agropecuário são distintos, sendo a diferença desses dados maior ao nível de espécies do que para o total de árvores cultivadas.

Diferenças significativas também surgem quando analisamos o total de árvores cultivadas existentes segundo os estados. A tabela 4 nos fornece esse resultado.

TABELA 4 - ARVORES CULTTVADAS EXISTENTES NOS ESTADOS BRASILEIROS (em mil arvores)

\begin{tabular}{|c|c|c|c|c|c|c|}
\hline \multirow[t]{2}{*}{ ESTADO } & \multicolumn{3}{|c|}{$31 / 12 / 75$} & \multicolumn{3}{|c|}{$31 / 12 / 80$} \\
\hline & $\begin{array}{l}\text { CENSO } \\
\text { (A) }\end{array}$ & $\underset{\text { (B) }}{\text { SIL VICULTURA }}$ & $\frac{(A-B)}{B}=100$ & $\begin{array}{c}\text { CENSO } \\
\text { (A) }\end{array}$ & $\begin{array}{l}\text { SIL VICULTURA } \\
\text { (B) }\end{array}$ & $\frac{(A-B)}{B}-100$ \\
\hline $\begin{array}{l}\text { Rondónia } \\
\text { Acre } \\
\text { Amazonas } \\
\text { Rorainas } \\
\text { Pará } \\
\text { Amapá } \\
\text { Maranhito } \\
\text { Plauf } \\
\text { Ceará } \\
\text { Rio Grande do Norte } \\
\text { Parafba } \\
\text { Pernambuco } \\
\text { Alagoas } \\
\text { Sergipe } \\
\text { Bahia } \\
\text { Minas Gerais } \\
\text { Espirito Santo } \\
\text { Rio de Jansiro } \\
\text { Sáo Paulo } \\
\text { Parana } \\
\text { Santa Catarina } \\
\text { Rio Grande do Sul } \\
\text { Mato Grosso do Sul } \\
\text { Mato Grosso } \\
\text { Goifs } \\
\text { Distrito Federal } \\
\end{array}$ & $\begin{array}{r}0 \\
0 \\
1.283 \\
0 \\
75.112 \\
0 \\
339 \\
12 \\
945 \\
1.415 \\
889 \\
16.457 \\
7 \\
72 \\
8.597 \\
1.040 .053 \\
161.180 \\
59.158 \\
1.598 .686 \\
828.742 \\
396.342 \\
700.506 \\
439.751 \\
4.415 \\
27.876 \\
497 \\
\end{array}$ & $\begin{array}{r}342 \\
0 \\
0 \\
0 \\
21.143 \\
1.118 \\
150 \\
0 \\
3.226 \\
56 \\
674 \\
18.389 \\
326 \\
61 \\
17.777 \\
1.101 .407 \\
136.750 \\
42.315 \\
2.062 .201 \\
824.345 \\
448.925 \\
625.154 \\
219.557 \\
\\
47.026 \\
2.464 \\
\end{array}$ & $\begin{array}{r}\overline{-} \\
\overline{-} \\
255, \overline{3} \\
126 \\
-\overline{6} \\
-70, \overline{7} \\
2,426,8 \\
31,9 \\
-10,5 \\
-97,9 \\
18 \\
-51,6 \\
-4,8 \\
17,9 \\
39,8 \\
-22,5 \\
0,5 \\
-11,7 \\
12,1 \\
100,3 \\
-40,7 \\
-79,8 \\
\end{array}$ & $\begin{array}{r}0 \\
0 \\
475 \\
0 \\
66.240 \\
28.373 \\
945 \\
0 \\
157 \\
188 \\
469 \\
10.988 \\
331 \\
564 \\
186.711 \\
2.959 .508 \\
203.450 \\
70.605 \\
1.686 .065 \\
1.235 .367 \\
775.663 \\
1.005 .289 \\
790.593 \\
33.671 \\
137.426 \\
34.334 \\
\end{array}$ & $\begin{array}{r}1.444 \\
0 \\
50 \\
0 \\
83.286 \\
43.456 \\
171 \\
0 \\
2.975 \\
198 \\
1.742 \\
18.177 \\
738 \\
1.788 \\
348.278 \\
2.550 .288 \\
215.032 \\
58.514 \\
2.233 .148 \\
1.314 .950 \\
644.571 \\
809.121 \\
772.964 \\
3.748 \\
114.833 \\
35.011 \\
\end{array}$ & $\begin{array}{r}- \\
\bar{y} \\
850 \\
-20,5 \\
-34,7 \\
452,6 \\
-\overline{7} \\
-94,7 \\
-5,1 \\
-73,1 \\
-39,5 \\
-55,1 \\
-68,5 \\
-46,4 \\
16 \\
-5,4 \\
20,7 \\
-24,5 \\
-6,1 \\
20,3 \\
24,2 \\
2,3 \\
798,4 \\
19,7 \\
-1,9\end{array}$ \\
\hline BRASIL & 5.371 .340 & 5.573 .406 & $-3,6$ & 9.227 .460 & 9.254 .483 & $-0,3$ \\
\hline
\end{tabular}

FONTE: Censos Agropecuários do Brasil de 1975 e 1980 e Silviculara 1975 e 1980.

Analisando a tabela 4, constatamos que:

- as maiores diferenças relativas entre os dados do Censo A gropecuário e da publicação Silvicultura ocorrem. de modo geral, para os estados que pouco reflorestaram.

- Segundo os dados dos Censos Agropecuários, ocorreu uma redução do número de árvores cultivadas existentes no Pará, no Rio Grande do Norte e na Parafba entre 1975 e 1980. Já a publicação Silvicultura indica um crescimento do número de árvores cultivadas existentes nesses estados para o citado qüinqüênio.

Portanto, os dados do Censo Agropecuário e da Silvicultura sobre o número de árvores cultivadas existentes devem ser considerados como alternativos. Pelo fato dos dados dos Censos Agropecuários serem obtidos por inquerito com toda a população de produtores e empresas reflorestadoras e a publicação Silvicultura trabalhar com uma amostra deles e com informantes indiretos, deve-se dar preferência aos dados do Censo 
Agropecuário em relação aos dados da Silvicultura.

Mas isso não inutiliza o uso dos dados sobre número de árvores cultivadas existentes da publicação Silvicultura, pois diversas outras fontes de dados sobre produção e preço no setor agropecuário, tanto do IBGE como de outras instituições de pesquisa, adotam procedimento similar (veja o caso da publicação Produção Extrativa Vegetal do IBGE e os dados de preços agricolas do Instituto de Economia Agrfcola da Secretaria de Agricultura e Abastecimento do Estado de São Paulo). Além disso, a definição de área reflorestada da publicação Silvicultura ê melhor do que o Censo Agropecuário.

\section{A EXPANSĀO DO REFLORESTAMENTO NO BRASIL E SUA CONCENTRAÇÃo POR ESTADOS}

Tanto os dados dos Censos Agropecuários quanto os da publicação Silvicultura (tabela 5 a 7) indicam o avanço do reflorestaminto no Brasil e suit concentração nos Estados de Minas Gerais, São Paulo, Paraná, Santa Catarina, Rio Grande do Sul e Mato Grosso do Sul.

TABELA 5 - ARVORES CULTTVADAS EXISTENTES NOS ESTADOS BRASILEIROS

\begin{tabular}{|c|c|c|c|c|c|c|c|c|}
\hline \multirow[t]{2}{*}{ ESTADO } & \multicolumn{2}{|c|}{$31 / 12 / 70$} & \multicolumn{2}{|c|}{$31 / 12775$} & \multicolumn{2}{|c|}{$31 / 12 / 80$} & \multicolumn{2}{|c|}{$31 / 12 / 85$} \\
\hline & $\begin{array}{c}\text { Número } \\
\text { (mil árvores) }\end{array}$ & Percentagem & $\begin{array}{l}\text { Número } \\
\text { (mil f́rvores) }\end{array}$ & Percentagen & $\begin{array}{l}\text { Número } \\
\text { (mil árvores) }\end{array}$ & Percentagem & $\begin{array}{l}\text { Número } \\
\text { (mil arvores) }\end{array}$ & Percentagem \\
\hline 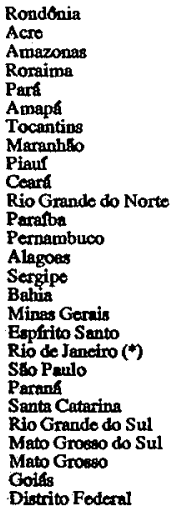 & $\begin{array}{r}0 \\
0 \\
3 \\
0 \\
69 \\
0 \\
\overline{1} \\
15 \\
2 \\
10 \\
40 \\
26 \\
8.318 \\
90 \\
617 \\
111 \\
467.239 \\
26.204 \\
13.632 \\
937.778 \\
282.178 \\
185.553 \\
643.526 \\
605 \\
20.699 \\
179\end{array}$ & $\begin{array}{r}0,00 \\
0,00 \\
0,00 \\
0,00 \\
0,00 \\
0,00 \\
0,0 \\
0,00 \\
0,00 \\
0,00 \\
0,00 \\
0,00 \\
0,32 \\
0,00 \\
0,02 \\
0,00 \\
18,07 \\
1,01 \\
0,52 \\
36,26 \\
10,91 \\
7,18 \\
24,89 \\
0,02 \\
0,80 \\
0,00\end{array}$ & $\begin{array}{r}0 \\
0 \\
1.283 \\
0 \\
75.112 \\
0 \\
- \\
339 \\
12 \\
945 \\
1.415 \\
889 \\
16.457 \\
7 \\
72 \\
8.597 \\
1.049 .053 \\
161.180 \\
59.158 \\
1.598 .686 \\
828.742 \\
396.342 \\
700.506 \\
439.751 \\
4.415 \\
27.876 \\
497\end{array}$ & $\begin{array}{r}0,00 \\
0,00 \\
0,02 \\
0,00 \\
1,40 \\
0,00 \\
0, \overline{0} \\
0,00 \\
0,02 \\
0,03 \\
0,02 \\
0,31 \\
0,00 \\
0,00 \\
0,16 \\
19,53 \\
3,00 \\
1,10 \\
29,76 \\
15,43 \\
7,38 \\
13,04 \\
8,19 \\
0,08 \\
0,52 \\
0,00\end{array}$ & $\begin{array}{r}0 \\
0 \\
475 \\
0 \\
66.240 \\
28.373 \\
- \\
945 \\
0 \\
157 \\
188 \\
469 \\
10.988 \\
331 \\
564 \\
186.711 \\
2.959 .508 \\
203.450 \\
70.605 \\
1.686 .065 \\
1.25 j .367 \\
775.663 \\
1.005 .289 \\
790.593 \\
33.671 \\
137.426 \\
34.334\end{array}$ & $\begin{array}{r}0,00 \\
0,00 \\
0,00 \\
0,00 \\
0,72 \\
0,31 \\
0,00 \\
0,00 \\
0,00 \\
0,00 \\
0,00 \\
0,12 \\
0,00 \\
0,00 \\
2,02 \\
32,07 \\
2,20 \\
0,77 \\
18,27 \\
13,39 \\
8,41 \\
10,89 \\
8,57 \\
0,36 \\
1,49 \\
0,37\end{array}$ & $\begin{array}{r}8 \\
0 \\
0 \\
500 \\
88.131 \\
84.446 \\
3.499 \\
27.116 \\
5 \\
16 \\
462 \\
1 \\
3.557 \\
14 \\
1.681 \\
447.680 \\
3.011 .201 \\
171.718 \\
55.883 \\
1.679 .537 \\
1.331 .033 \\
769.679 \\
1.203 .052 \\
607.698 \\
19.982 \\
142.532 \\
31.027\end{array}$ & $\begin{array}{r}0,00 \\
0,00 \\
0,00 \\
0,00 \\
0,91 \\
0,87 \\
0,04 \\
0,28 \\
0,00 \\
0,00 \\
0,00 \\
0,00 \\
0,04 \\
0,00 \\
0,02 \\
4,62 \\
31,07 \\
1,77 \\
0,68 \\
17,33 \\
13,74 \\
7,94 \\
12,41 \\
6,27 \\
0,21 \\
1,47 \\
0,32\end{array}$ \\
\hline BRASIL & 2.585 .984 & 100,00 & 5.371 .340 & 100,00 & 9.227 .460 & 100,00 & 9.690 .493 & 100,00 \\
\hline
\end{tabular}




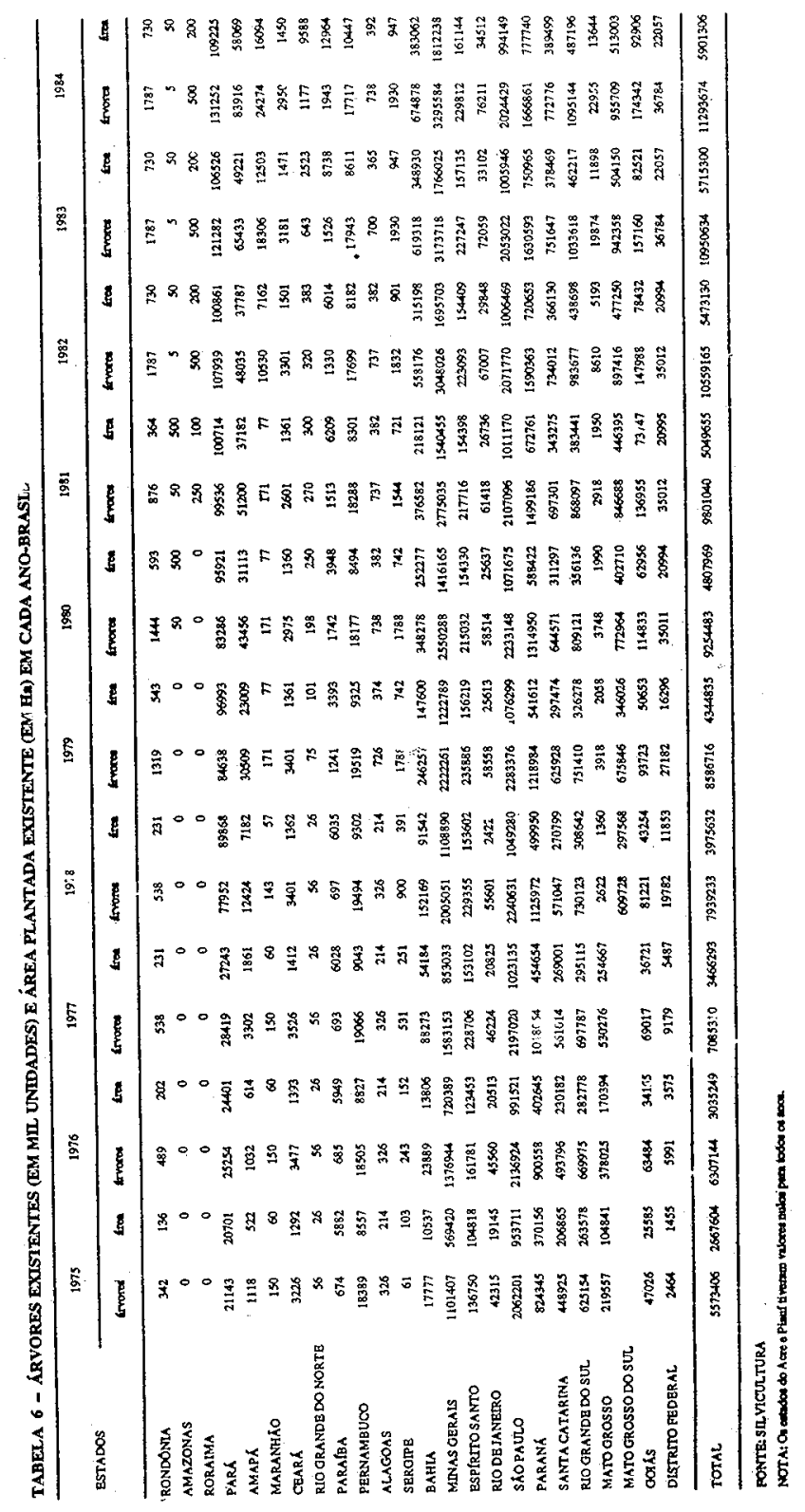




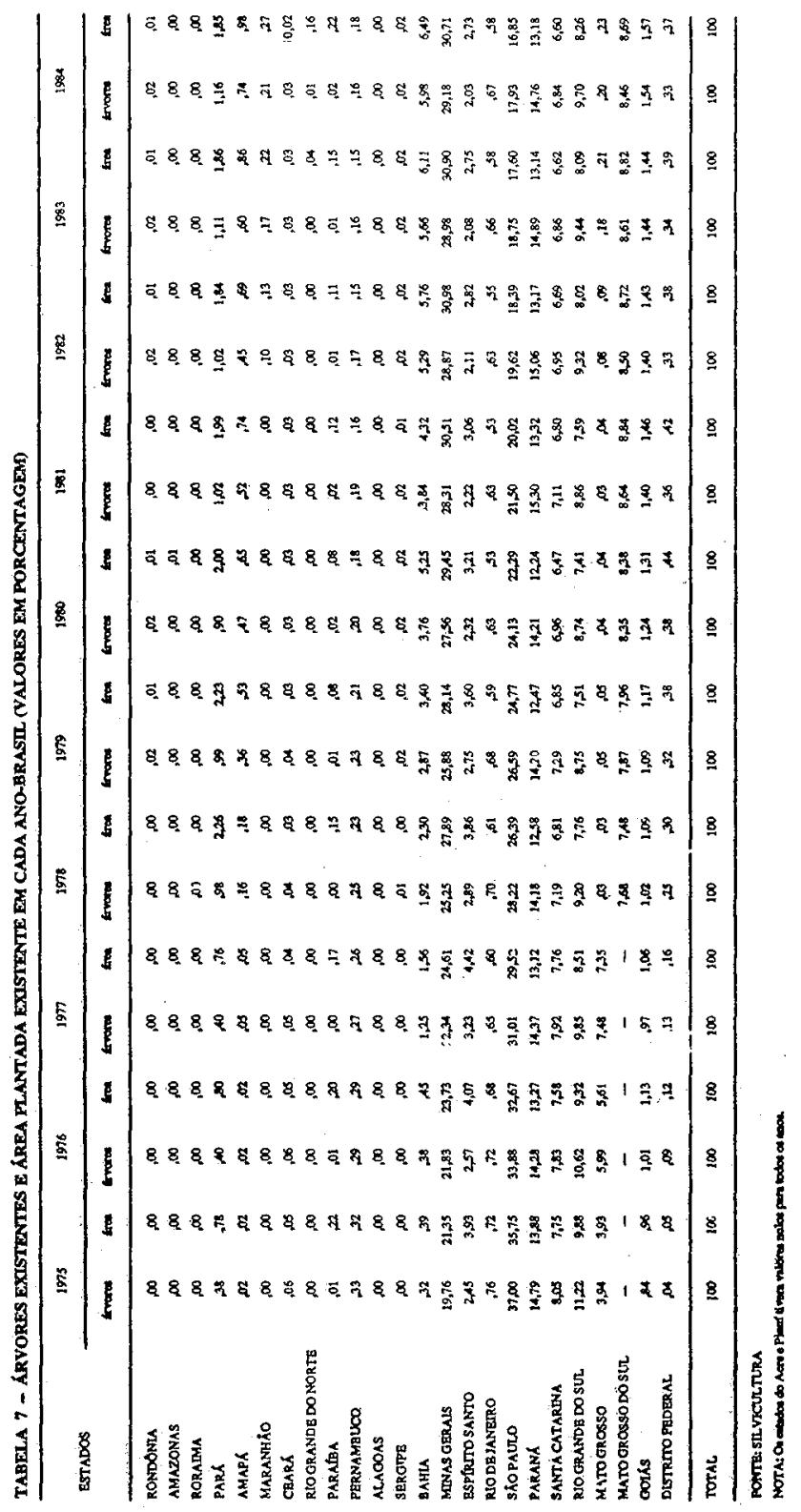


O reflorestamento é pouco expressivo nas regiōes Norte e Nondeste, com exceção do Pará e da Bahia.

No Pará, o reflorestamento ocorreu devido ao impacto do Projeto Jari. Na tabela 6, os dados de árvores e área existente no Pará em $31 / 12 / 75,31 / 12 / 76$ e em 31/12/77 estão subestimados. Durante esses anos a gmelina não foi computada. Isso ocorreu a partir de 1978. Como o número de árvores e área ocupada com essa espécie é grande em relação ao plantio no Pará, surgiu em salto no número de árvores e área existente em $31 / 12 / 78$ em relação a $31 / 12 / 77.5$

Na Bahia, o reflorestamento e feito para produzir carvão vegetal para as siderurgias a carvão vegetal, concentradas em Minas Gerais, e para fornecer materia-prima para a indústria de celulose. $O$ reflorestamento na Bahia foi favorecido pela modificação na sistemática de concessão de incentivos fiscais do FISET/Reflorestamento a partir de 1980. Segundo BACHA (1991, p. 150-151), "Em fins de 1979, o Conselho de Desenvolvimento Económico determinou que os recursos do Fiset-Florestamento e Reflorestamento fossem aplicados prioritariamente nos Estados localizados na área de atuação da Sudene, estabelecendo os seguintes percentuais mínimos do fundo a serem alocados para essa área: $30 \%$ em 1980, 40\% em 1981 e 50\% a partir de 1982". Para não se distanciar da área consumidora de madeira, lenha e carvão, as empresas reflorestadoras optaram por concentrar o plantio no vale do Jequitinhonha de Minas Gerais e na Bahia.

Utilizando os dados de área ocupada com o plantio de árvores com fins de madeira, podemos comparar o espaço f́́sico qưe ocupa com o utilizado pelas principais culturas. Observando a tabela 8, constatamos que o avanço do espaço físico ocupado pelas árvores plantadas foi maior do que o verificado para diversas culturas. Em 1975, as áreas colhidas com algodão, arroz em casca, feijão, milho, soja ou trigo eram maiores do que a área ocupada pelas árvores plantadas. Em 1984, apenas milho e suja tinham área colhida maior do que a ocupada pelas árvores plantadas.

5 Em 31/12/78 foi computado, como existindo, 49.553 mil arvores cultivadas de gmelina no Pará. Somando-as com as 28.419 mil árvores cultivadas de todas as espécies existentes no Pará em 31/12/77 encontramos um valor próximo dos 77.952 mil árvores cultivadas, de todas as espécies, existentes no Pará em 31/12/78. 
tabela 8 - Areas COLHidas COM Certos produtos agrícolas e ocupada COM ÁRVORES CULTTVADAS (em mil ha)

\begin{tabular}{|c|c|c|c|c|c|c|c|c|c|c|}
\hline ANO & Algod丸́o & $\begin{array}{c}\text { Arroz em } \\
\text { Casca }\end{array}$ & Cafe & $\begin{array}{l}\text { Cana-de- } \\
\text { Açacar }\end{array}$ & Feeijæo & Mandioca & Milho & Soja & Trigo & $\begin{array}{l}\text { Floresta } \\
\text { Plantada }\end{array}$ \\
\hline 1975 & 3.876 & 5.306 & 2.217 & 1.969 & 4.146 & 2041 & 10.855 & 5.824 & 2.932 & 2.668 \\
\hline 1976 & 3.409 & -6.656 & 1.121 & 2.093 & 4.059 & 2.094 & 11.118 & 6.417 & 3.540 & 3.035 \\
\hline 1977 & 4.097 & 5.992 & 1.941 & 2.270 & 4.551 & 2.176 & 11.797 & 7.070 & 3.153 & 3.466 \\
\hline 1978 & 3.951 & 5.624 & 2.184 & 2.391 & 4.617 & 2.149 & 11.125 & 7.782 & 2.811 & 3.976 \\
\hline 1979 & 3.646 & 5.452 & 2,406 & 2537 & 4.212 & 2.111 & 11.319 & 8.256 & 3.831 & 4.345 \\
\hline 1980 & 3.699 & 6.243 & 2.434 & 2.608 & 4,643 & 2.016 & $11 . A 51$ & 8.774 & 3.122 & 4.808 \\
\hline 1981 & 3.511 & 6.102 & 2.618 & 2.826 & 5.027 & 2.067 & 11.520 & 8.501 & 1.920 & 5.050 \\
\hline 1982 & 3.624 & 6.025 & 1.895 & 3.084 & 5.926 & 2.122 & 12.620 & 8.203 & 2.828 & 5.473 \\
\hline 1983 & 2.926 & 5.108 & 2.346 & 3.479 & 4.064 & 2.061 & 10.706 & 8.137 & 1.879 & 5.715 \\
\hline 1984 & 3.114 & 5.351 & 2.505 & 3.656 & 5.320 & 1.816 & 12.018 & 9,421 & 1.742 & 5.901 \\
\hline
\end{tabular}

FONTE: Rstatrsticas Historicas Do Brasil, IBGE, 2" Ediç̧o, Rio de Janeiro, 1990 e Silvicultura (varios números).

\section{CONCLUSÃO}

Em nosso trabalho procuramos discutir as fontes de dados disponiveis sobre o reflorestamento no Brasil evidenciando as suas limitações. Chegamos à conclusão de que os melhores dados são os dados Censos Agropecuários e os da publicação Silvicultura.

Se a nossa preocupação for quanto ao número de árvores cultivadas existentes, deve ser dado preferência aos dados dos Censos Agropecuários, sempre que possivel, pois são obtidos por inquérito com toda a população. Já a área ocupada com matas plantadas dos Censos Agropecuários sobrestima a área efetivamente reflorestada. Os dados dos cadastros do IBDF devem ser utilizados para fins restritos, pois referem-se apenas aos plantios que deveriam ter sido realizados com incentivos fiscais e não ao total de plantios realizados.

Constatamos pela análise dos ciados do Censo Agropecuário e da Silvicultura que:

- houve um rápido avanço do reflorestamento no Brasil de 1970 a 1984. A área ocupada com árvores plantadas em 1964 era cerca de 500 mil hectares (COOPERCOTIA, 1965) e em 31/12/84 era 5.901 mil hectarcs. Em 20 anos multiplicamos a área reflorestada em quase 12 vezes.

- O reflorestamento concentra-se nos estados de Minas Gerais, São Paulo, Parana, Santa Catarina, Rio Grande do Sul e Mato Grosso do Sul. - Em 1984, a área ocupada com árvores cultivadas existentes era menor que a área colhida com soja e milho, mais maior do que a área colhida com as outras principais culturas.

Apesar desse texto ter um carăter descritivo, suas informações po- 
dem ser úteis para análise sobre polf́ticas de reflorestamento no Brasil. Por exemplo, considerando a evolução do reflorestamento no Brasil analisado nesse texto, seria possivel uma meta como a do Projeto Floram (reflorestar 20 milhōes de hectares em 20 a 30 anos)? O que fazer na Região Norte, área onde o desmatamento avança rapidamente e o reflorestamento $e$ insignificante? Essas e outras perguntas podem ser respondidas em outros trabalhos.

\section{BHBI,IOGRAFIA}

ASSIS, J. B.; SILVA, E. \& ARAÚJO, J. C. A. Desempenho do Reflorestamento em Pequenos e Médios Imóveis Rurais na Zona da Mata, Informe Agropecuário, v. 12, n. 141, p. 90-94. set. 1986.

BACHA, C. J. C. A Expansão da Silvicultura no Brasil Revista Brasileira de Economia, v. 45, n. 1, p. 145-168, jan./mar. 1991.

BEATTIE, W. D. \& FERREIRA, J. M. Diagnóstico do Subsetor Florestal no Brasil Ańlise Financeira e Sócio-Economica do Reflorestamento no Brasil. COPLAN-IBDF, Ministério da Agricultura, 1978.

BERGAMASCO, A.\& BERGAMASCO, S. M. P. P. O Programa de Reflorestamento de Pequenos e Médios Imóveis Rurais (REPEMIR) no Estado de São Paulo: Uma Avaliação Preliminar. Anais do 1\% Encontro Brasileiro de Economia Florestal, 23-27 de maio de 1988, Curitiba, 20 vol., p. 79-98.

COOPERATIVA. Machado Desafia Reflorestamento. COOPERATIVA, v. 22, n. 183, p. 2024 , jan. 1965.

EXAME. Energia, O Novo Impulso Para os Negocios da Madeira. Exame, n. 211, p. 30-37, out. 1980.

IBDF. O Setor Florestal Brasileiro 79/85. Braślia, Ministério da Agricultura, Instituto Brasileiro de Desenvol vimento Florestal, 1985.

SILVA, Sebastião. Algarobeira (Prosopis Julifiora (Sw) D. C ) no Nordeste do Brasil Ministério da Agricultura, Secretaria Nacional de Produção Agropecuária, Secretaria da Produç̆o Animal, Brastlia, 1989.

\section{ABSTRACT \\ DATA SURVEY OF REFORESTATION IN BRAZIL}

The goal of this study was to analyze data sources concerning forestation in Brazil. Agricultura census data published by Silviculture and data originated from the former Brazilian Institute of Forestation Development (IBDF), were alanyzed.

We conclude that, whenever possible, should be given priority to Agricultural Census data. It is not excluded to use data published by Silviculture, when focus analysis reforestation area. But data from IBDF sources must be used with caution.

The analysis of Agricultural Census and Silviculture data indicate a hyge growth in reforestation in Brazil, but it must be stressed that forestation is concentrated in the states of Minas Gerais, Săo Paulo, Paraná, Santa Catarina, Rio Grande do Sul and Mato Grosso do Sul. 